\title{
Impact of Pre-Revascularization and Post-Revascularization Cardiac Arrest on Survival Prognosis in Patients With Acute Myocardial Infarction and Following Emergency Percutaneous Coronary Intervention
}

\author{
Changzuan Zhou ${ }^{1,2 t}$, Qingcheng Lin ${ }^{1 \dagger}$, Guangze Xiang ${ }^{1}$, Mengmeng Chen ${ }^{1}$, \\ Mengxing Cai ${ }^{1}$, Qianli Zhu ${ }^{1}$, Rui Zhou ${ }^{3}$, Weijian Huang ${ }^{1}$ and Peiren Shan ${ }^{1 *}$

\begin{abstract}
${ }^{1}$ Department of Cardiology, The Key Laboratory of Cardiovascular Disease of Wenzhou, The First Affiliated Hospital of Wenzhou Medical University, Wenzhou, China, ${ }^{2}$ Department of Cardiology, Wenzhou Hospital of Integrated Traditional Chinese and Western Medicine, Wenzhou, China, ${ }^{3}$ Department of Cardiology, Wenzhou People's Hospital, Wenzhou, China
\end{abstract}

OPEN ACCESS

Edited by:

Da Yin,

Dalian Medical University, China

Reviewed by:

Shaoping Nie,

Capital Medical University, China

Yao-Jun Zhang,

Xuzhou Cancer Hospital, China

*Correspondence:

Peiren Shan

prshan@126.com

tThese authors have contributed equally to this work

Specialty section:

This article was submitted to

Coronary Artery Disease,

a section of the journal

Frontiers in Cardiovascular Medicine

Received: 06 July 2021

Accepted: 11 October 2021

Published: 19 November 2021

Citation:

Zhou C, Lin Q, Xiang G, Chen M, Cai M, Zhu Q, Zhou R, Huang $W$ and

Shan $P$ (2021) Impact of

Pre-Revascularization and

Post-Revascularization Cardiac Arrest on Survival Prognosis in Patients With

Acute Myocardial Infarction and

Following Emergency Percutaneous

Coronary Intervention.

Front. Cardiovasc. Med. 8:705504.

doi: 10.3389/fcvm.2021.705504
Objectives: To evaluate the effects of occurrence and timing of sudden cardiac arrest (SCA) on survival in patients with acute myocardial infarction (AMI) who underwent emergency percutaneous coronary intervention (PCI).

Methods: We analyzed 1,956 consecutive patients with AMI with emergency PCl from 2014 to 2018. Patients with cardiac arrest events were identified, and their medical records were reviewed.

Results: Patients were divided into non-cardiac arrest group (NCA group, $n=1,724$ ), pre-revascularization cardiac arrest (PRCA group, $n=175$ ), and post-revascularization SCA (POCA group, $n=57$ ) according to SCA timing. Compared to NCA group, PRCA group and POCA group presented with higher brain natriuretic polypeptide (BNP), more often Killip class $3 / 4$, atrial fibrillation, and less often completed recovery of coronary artery perfusion (all $p<0.05$ ). Both patients with PRCA and POCA showed increased 30-day all-cause mortality when compared to patients with NCA (8.0 and $70.2 \%$ vs. $2.9 \%$, both $p<0.001$ ). However, when compared to patients with NCA, patients with PRCA did not lead to higher mortality during long-term follow-up (median time 917 days) ( 16.3 vs. $18.6 \%, p=0.441)$, whereas patients with POCA were associated with increased all-cause mortality (36.3 vs. $18.6 \%, p<0.001$ ). Multivariate analysis identified Killip class $3 / 4$, atrial fibrillation, high maximum MB isoenzyme of creatine kianse, and high creatinine as predictive factors for POCA. In Cox regression analysis, POCA was found as a strong mortality-increase predictor $(\mathrm{HR}, 8.87$; 95\% Cl, 2.26-34.72; $p=0.002)$ for long-term all-cause death.

Conclusions: POCA appeared to be a strong life-threatening factor for 30-day and long-term all-cause mortality among patients with AMI who admitted alive and underwent emergency PCl. However, PRCA experience did not lead to a poorer long-term survival in patients with AMI surviving the first 30 days.

Keywords: cardiac arrest, resuscitation, acute myocardial infarction, survival, percutaneous coronary intervention (PCI) 


\section{INTRODUCTION}

Sudden cardiac arrest (SCA) was one of the leading causes of mortality in patients with coronary artery disease (CAD). Among survivors of cardiac arrest occurring pre-hospitalization, CAD was present in more than $70 \%$ in one study (1), with total occlusion of culprit vessels in half of them; and $71 \%$ in another study, with $43 \%$ presenting with acute myocardial infarction (AMI) (2). The coronary angiographic assessment documented culprit vessels in $92.7 \%$ of SCA survivors presenting with ST-elevation myocardial infarction (STEMI) and in $69.2 \%$ of those without ST-segment elevation. Coronary angiography and percutaneous coronary intervention (PCI) are key components of the management of SCA complicated with STEMI or non-STEMI (NSTEMI) $(3,4)$. Despite significant advances in life-supporting and post-arrest management, high in-hospital mortality and poor post-hospitalization prognosis were still observed in SCA populations. Recent studies have also yielded inconsistent results on whether emergency PCI benefits survival in patients with SCAs (5-7). Moreover, a long-term outcome analysis performed in non-selected patients with AMI, regarding influence of timing of SCA, is lacking. Here, we investigated the impact of occurrence and timing (pre-revascularization and post-revascularization) of witnessed SCA on short-term and long-term mortality in nonselected patients who underwent emergency PCI.

\section{METHODS}

\section{Study Setting and Study Population}

This study enrolled patients with AMI who underwent emergency coronary angiography and subsequent PCI between January 2014 and October 2018 in the First Affiliated Hospital of Wenzhou Medical University. All patients were initially diagnosed with AMI at admission and underwent emergency PCI. This research was approved by the Ethics Committee of the First Affiliated Hospital of Wenzhou Medical University and performed according to the principles of the Declaration of Helsinki. Participants provided written informed consent, and their details were kept anonymized. The diagnosis of AMI was based on the detection of the rise of troponin I above 99th percentile of upper reference limit together with at least one of the following evidence of myocardial infarction: (1) symptoms of ischemia, including various combinations of chest discomfort, (2) ECG changes, indicative of new ischemia, (3) development of pathological Q waves in the ECG, and (4) imaging evidence of new loss of viable myocardium or new regional wall motion abnormality. Patients with AMI with SCA were classified as pre-revascularization cardiac arrest (PRCA) group and postrevascularization cardiac arrest (POCA) group according to the timing of SCA. Patients with AMI without SCA were enrolled in non-cardiac arrest (NCA) group. The exclusion criteria were: (1) incomplete invasive coronary angiography image data; (2) missing records on SCA occurrence, and (3) clinical and angiography data not supporting a diagnosis of AMI.

\section{Data Collection}

To ensure data integrity, consistency, and comparability, the investigators were trained before inputting the required information extracted from the clinical records of each patient. The demographic and medical history data included age, sex, hypertension, diabetes mellitus, hyperlipidemia, cerebrovascular disease history, previous smoking history, and alcohol drinking history. The blood laboratory examinations, including brain natriuretic polypeptide (BNP), D-D dimer, lactate, creatinine, glucose, triglyceride, and low-density lipoprotein cholesterol (LDL-c) were determined upon hospital admission. Clinical presentation data included timing of SCA (PRCA and POCA), type of AMI (e.g., STEMI and NSTEMI), atrial fibrillation, use of vasoactive drugs (including inotropes, dobutamine, vasopressors, etc.), and use of intra-aortic balloon pump (IABP). Invasive data collected from cardiac catheterization laboratory records included percentage stenosis of affected coronary vessel, culprit coronary vessel [e.g., left anterior descending artery (LAD), left main (LM) artery, left circumflex artery (LCX), and right coronary artery (RCA)], thrombolysis in myocardial infarction (TIMI) flow grade before and after intervention, implantation of drug-eluting stents, use of thrombus aspiration, and corrected TIMI frame count (CTFC). Culprit vessel calcification was qualitatively stratified in four degrees by reviewing coronary angiographic images. Calcification class 0 , no calcification is visible in culprit vessels; calcification class 1 , mild and obscure calcification, which can only be observed in culprit vessels when the ventricular walls were moving; calcification class 2 , moderate and clear calcification, which can only be observed in culprit vessels when the ventricular walls were moving; and calcification class 4 , remarkable calcification can be observed in culprit vessels whether the ventricular walls were moving or not.

\section{Definitions}

Sudden cardiac arrest was defined as the absence of heartbeats and respiration requiring CPR for recovery. Shockable rhythm was defined as pulseless ventricular tachycardia (pVT) and ventricular fibrillation (VF), which could benefit from electric defibrillation, whereas non-shockable rhythm contained other pulseless electrical activities and asystole rhythm. LM or ostial LAD stenosis was defined as more than $50 \%$ vessel stenosis in LM or ostial LAD. Three-vessel disease was defined as more than three vessels stenosis $>50 \%$. CTFC was calculated from the first frame in which dye fully entered the artery to the time point contrast fluid reached standardized distal landmarks at a frame rate of 30 frames/s during coronary angiography. The developed symptom of heart failure included New York Heart Association class III/IV dyspnea, orthopnea, and rales greater than onethird lung fields thought to be related to cardiac dysfunction. Ventricular arrhythmia was defined as sustained $\mathrm{pVT}$ and VF.

The main outcomes of interest were 30-day all-cause mortality and long-term survival prognosis in 30-day survivors. Major adverse cardiac and cerebrovascular events (MACCE) were defined as a composite of recurrent myocardial infarction, admission for unstable angina, ventricular tachycardia/ventricular fibrillation, cerebral ischemic, and major bleeding event.

\section{Follow-Up and Survival Data}

The death dates were obtained by checking inpatient department records and telephone follow-up. The last telephone follow-up 


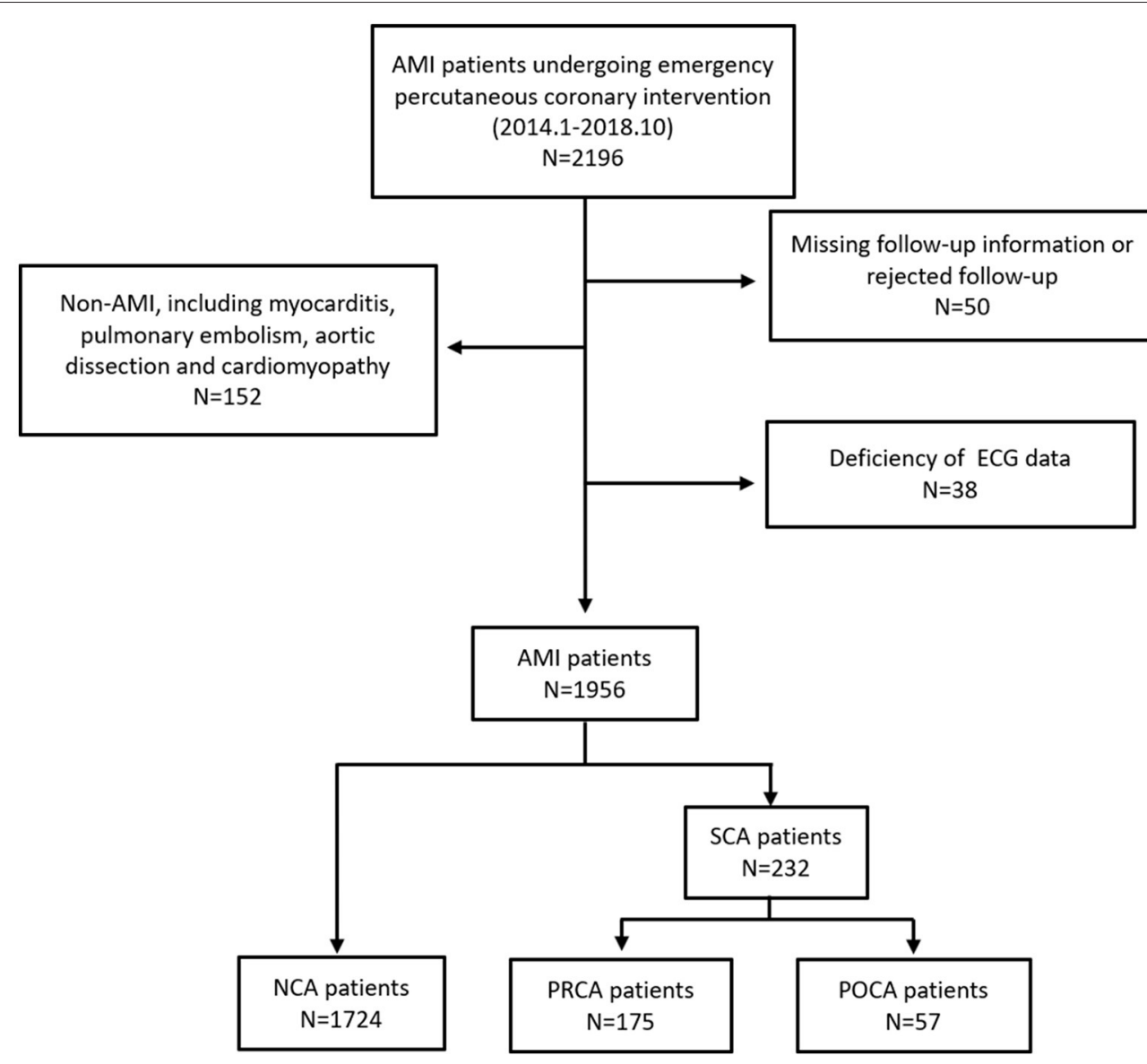

FIGURE 1 | Study population. NCA, non-cardiac arrest; POCA, post-revascularization cardiac arrest; PRCA, pre-revascularization cardiac arrest.

was 1 June, 2019. And patients who lost to telephone follow-up were noted as censored at the last date they were known to be alive. The days from admission until censoring or death were calculated to be the follow-up time.

\section{Statistical Analysis}

Normally distributed continuous variables were analyzed by the Student-Newman-Keuls (SNK) test and presented as mean $\pm \mathrm{SD}$. The Wilcoxon rank-sum test was used to compare medians of non-normally distributed continuous variables that were analyzed by the Wilcoxon rank-sum test and presented as medians $(25,75$ th percentile). Differences between categorical variables were assessed with the Chi-square test, respectively. The univariate and multivariate stepwise Logistic regression analyses were used to identify POCA-related factors. Landmark analysis was performed to evaluate 30 -day and long-term survival prognosis, and the Log-rank test was used to compare KaplanMeier event rates among groups. The Kaplan-Meier curves were plotted by MedCalc 18 (MedCalc Software, Ostend, Belgium). Cox proportional hazards regression was used to determine risk factors associated with mortality during follow-up period in the studied population. A two-tailed $p<0.05$ was considered statistically significant. All statistical analyses were performed using STATA 13 (StataCorp LP, College Station, TX, USA).

\section{RESULTS}

\section{Baseline Clinical Characteristics}

This study initially enrolled 2,154 patients, and the final dataset consisted of 1,956 patients with a discharge diagnosis of AMI, including STEMI and NSTEMI during the study period, as described in Figure 1. Of those, SCA was recorded in 232 resuscitated patients, with 175 as PRCA and 57 as POCA. We found 5 patients experienced both PRCA and subsequent POCA events. These 5 patients were enrolled in PRCA group. As shown in Table 1, some baseline clinical characteristics of patients, including alcohol use, hypertension, and hyperlipidemia, were evenly distributed among the three groups. The NCA group and POCA group showed similar male gender proportion, 60.2 and $56.1 \%$, respectively $(p=0.540)$, whereas in the PRCA group the male gender $(72.0 \%)$ percentage was significantly higher than that in the NCA group $(p=0.002)$. Compared to the NCA group, the POCA group was more likely to be older age, more diabetes, lower proportion of smokers, and poorer ejection fraction (all $p<0.05)$. Compared to the NCA group, both PRCA and POCA 
TABLE 1 | Baseline characteristics.

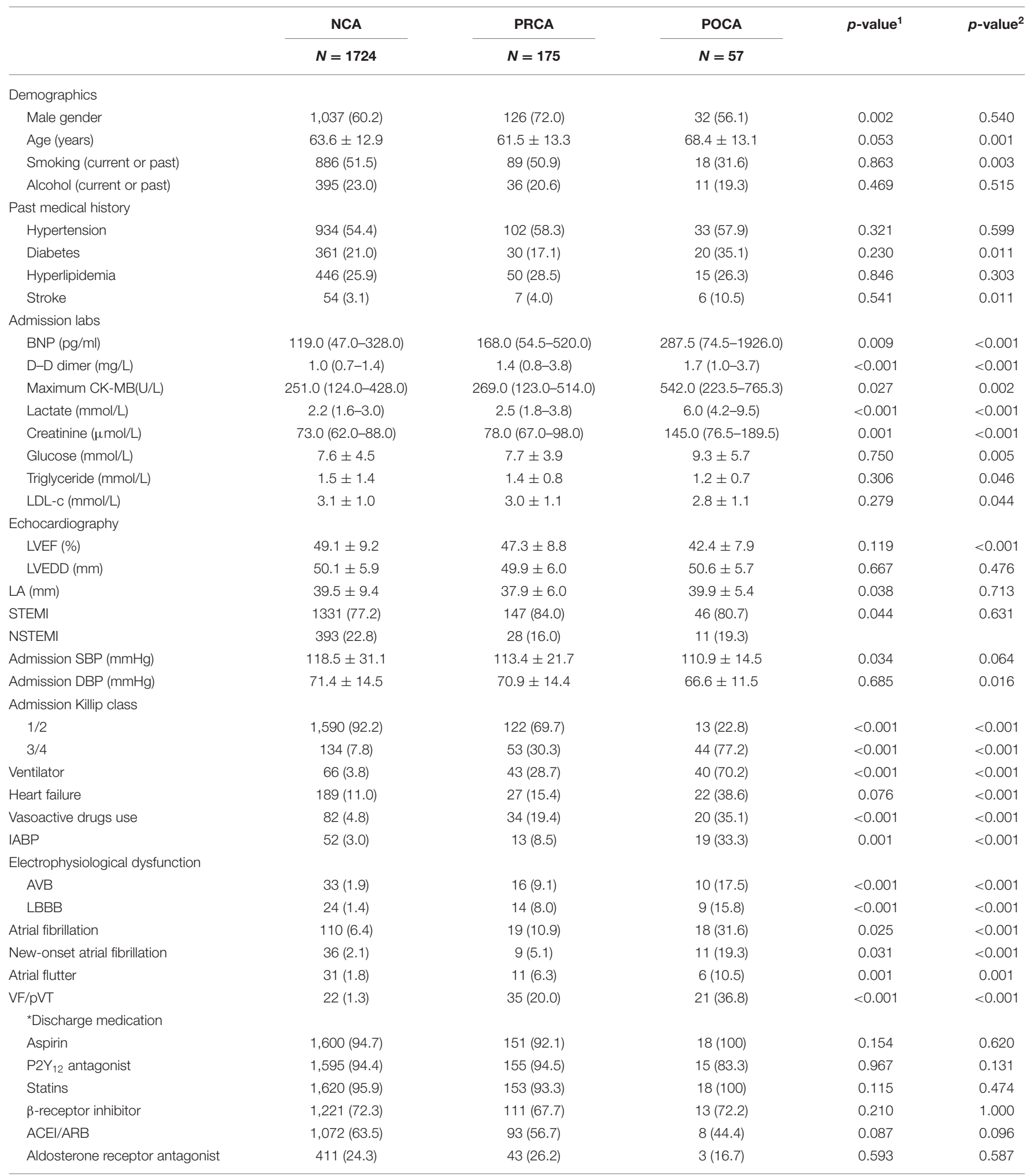

Data are presented as mean $\pm S D$, medians $\left(25,75\right.$ th) or $n(\%)$. p-value ${ }^{1}$, NCA group vs. PRCA group; p-value ${ }^{2}$, NCA group versus POCA group. *Discharge medication were analyzed in discharge survivors, with 1,689 patients in the NCA group, 164 patients in the PRCA group and 18 patients in the POCA group. AVB, atrioventricular block; BNP, brain natriuretic peptide; CK-MB, MB isoenzyme of creatine kianse; LA, left atrial diameter; $L B B B$, left bundle branch block; LDL-c, low-density lipoprotein cholesterol; LVEF, left ventricular ejection fraction; LVEDD, left ventricular end-diastolic dimension; IABP, intra-aortic balloon pump; IHCA, in-hospital cardiac arrest; NCA, non-cardiac arrest; NSTEMI, non-ST-segment elevation myocardial infarction; $P C I$, percutaneous coronary intervention; PRCA, pre-revascularization cardiac arrest; POCA, post-revascularization cardiac arrest; SCA, sudden cardiac arrest; STEMI, ST-segment elevation myocardial infarction; DBP, dilation blood pressure; SBP, systolic blood pressure; VF, ventricular fibrillation; pVT, pulseless ventricular tachycardia. 
TABLE 2 | Procedural characteristics.

\begin{tabular}{|c|c|c|c|c|c|}
\hline & NCA & PRCA & POCA & $p$-value ${ }^{1}$ & $p$-value ${ }^{2}$ \\
\hline & $N=1,724$ & $N=175$ & $N=57$ & & \\
\hline \multicolumn{6}{|l|}{ Culprit vessel } \\
\hline $\mathrm{LAD}$ & $887(51.5)$ & $72(41.1)$ & $25(43.9)$ & 0.009 & 0.259 \\
\hline LCX & $225(13.1)$ & $12(6.9)$ & $8(14.0)$ & 0.018 & 0.828 \\
\hline LM & $31(1.8)$ & $2(1.1)$ & $6(10.5)$ & 0.763 & $<0.001$ \\
\hline $\mathrm{RCA}$ & $578(33.5)$ & $87(49.7)$ & $16(28.1)$ & $<0.001$ & 0.390 \\
\hline LM or ostial LAD stenosis & $463(26.9)$ & $32(18.3)$ & $22(38.6)$ & 0.014 & 0.050 \\
\hline Vessel occlusion & $1,094(63.5)$ & $114(65.1)$ & $36(63.2)$ & 0.659 & 0.963 \\
\hline Culprit vessel stenosis (\%) & $96.6 \pm 7.9$ & $96.8 \pm 5.8$ & $97.4 \pm 5.1$ & 0.678 & 0.117 \\
\hline Three-vessel disease & $466(27.0)$ & $52(29.7)$ & $24(42.1)$ & 0.447 & 0.012 \\
\hline \multicolumn{6}{|c|}{ Calcification degree in culprit lesion } \\
\hline $0 / 1$ & 1,528 (88.6) & $160(91.4)$ & $48(84.2)$ & 0.262 & 0.304 \\
\hline 2 & $110(6.4)$ & $10(5.7)$ & $3(5.3)$ & 0.730 & 0.935 \\
\hline 3 & $86(5.0)$ & $5(2.9)$ & $6(10.5)$ & 0.676 & 0.120 \\
\hline CTO in non-culprit vessel & $114(6.6)$ & $15(2.9)$ & $5(8.8)$ & 0.326 & 0.427 \\
\hline Stent implantation & $1,496(87.0)$ & $150(85.7)$ & $43(76.8)$ & 0.624 & 0.026 \\
\hline Thrombus aspiration & $651(37.9)$ & $84(48.0)$ & $24(42.1)$ & 0.009 & 0.521 \\
\hline ICD/CRTD & $7(0.4)$ & $2(1.1)$ & 0 & 0.198 & 0.796 \\
\hline \multicolumn{6}{|l|}{ Pre-PCl TIMI } \\
\hline $0 / 1$ & $1,309(76.1)$ & $135(77.2)$ & $45(79.0)$ & 0.925 & 0.752 \\
\hline 2 & $166(9.6)$ & $13(7.4)$ & $2(3.5)$ & 0.343 & 0.164 \\
\hline 3 & $246(14.3)$ & $27(15.4)$ & $10(17.5)$ & 0.677 & 0.488 \\
\hline \multicolumn{6}{|l|}{ Post-PCI TIMI } \\
\hline $0 / 1$ & $22(1.3)$ & $4(2.3)$ & $2(3.5)$ & 0.079 & 0.094 \\
\hline 2 & $92(5.3)$ & $16(9.1)$ & $7(12.3)$ & 0.007 & 0.009 \\
\hline 3 & $1610(93.4)$ & $155(85.5)$ & $48(86.0)$ & 0.001 & 0.002 \\
\hline Post-PCI SBP (mmHg) & $122.6 \pm 22.7$ & $115.1 \pm 23.4$ & $110.5 \pm 19$ & $<0.001$ & $<0.001$ \\
\hline Post-PCI DBP (mmHg) & $74.6 \pm 14.5$ & $71.4 \pm 14.1$ & $66.9 \pm 12.6$ & 0.012 & $<0.001$ \\
\hline Post-PCI CTFC & $38.0(30.0-50.0)$ & $40.0(32.0-58.0)$ & $45.0(35.5-59.5)$ & 0.037 & 0.012 \\
\hline
\end{tabular}

Data are presented as mean $\pm S D, n$ (\%) or medians (25, 75th). p-value ${ }^{1}$, NCA group vs. PRCA group; p-value ${ }^{2}$, NCA group vs. POCA group. AMI, acute myocardial infarction; CRTD, cardiac resynchronization therapy defibrillator; CTFC, corrected TIMI frame count; CTO, chronic total occlusion; ICD, implantable cardioverter defibrillator; LAD, left anterior descending;

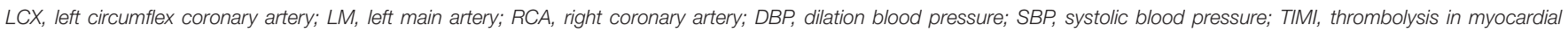
infarction; PCl, percutaneous coronary intervention; NCA, non-cardiac arrest; PRCA, pre-revascularization cardiac arrest; POCA, post-revascularization cardiac arrest.

groups showed higher levels of BNP, D-D dimer, maximum $\mathrm{MB}$ isoenzyme of creatine kianse (CK-MB), lactate, and creatinine (all $p<0.05)$. In the POCA group, the BNP was nearly three times the level of the NCA group (287.5 vs. $119.0 \mathrm{pg} / \mathrm{ml}, p<0.001$ ), and serum lactate was more than twice of the NCA group (6.0 vs. $2.2 \mathrm{mmol} / \mathrm{L}, p<0.001)$. We also found higher $\mathrm{D}-\mathrm{D}$ dimer concentration in patients with PRCA and POCA than in patients with NCA $(p<0.001)$.

Compared to patients in the NCA group, patients with PRCA were more likely to be STEMI ( 84.0 vs. $77.2 \%, p=0.044)$, whereas there was no significant of clinical presentation between the NCA group and POCA group. Patients with SCA had more often admission Killip class 3/4, ventilator use, IABP, and vasoactive drugs use compared to patients in the NCA group (all $p<0.05$ ). Moreover, patients with SCA had more frequent heart failure and electrophysiological dysfunction, including atrioventricular block, left bundle branch block, ventricular arrhythmia (VF/pVT), atrial fibrillation, and atrial flutter (all $p<0.05)$.

As presented in Table 2, no intergroup difference was observed in discharge medication, which included aspirin, P2Y12 antagonist, $\beta$-receptor inhibitor, angiotensin-converting enzyme inhibitor, angiotensin receptor blockers, statins, and aldosterone receptor antagonists (all $p>0.05$ ).

\section{Procedural Characteristics}

According to cardiac catheterization laboratory data (Table 2), the culprit vessel of LM artery was more likely to be observed in the POCA group when compared to that in the NCA group ( 10.5 vs. $1.8 \%, p<0.001$ ). There was a higher proportion of LM or ostial LAD stenosis in patients with POCA than in patients with NCA (38.6 vs. $26.9 \%, p=0.050$ ). Culprit vessel of LAD and LCX were less commonly observed in the PRCA group when compared to the NCA group $(p=0.009$ and $p=0.018)$. However, 
TABLE 3 | Cumulative mortality in patients with AMI stratified by timing of SCA.

\begin{tabular}{|c|c|c|c|c|c|}
\hline & $\begin{array}{c}\text { NCA } \\
N=1724\end{array}$ & $\begin{array}{c}\text { PRCA } \\
N=175\end{array}$ & $\begin{array}{l}\text { POCA } \\
N=57\end{array}$ & $p$-value ${ }^{1}$ & $p$-value ${ }^{2}$ \\
\hline In-hospital mortality & $35(2.0)$ & $11(6.3)$ & $39(68.4)$ & 0.002 & $<0.001$ \\
\hline 30-day mortality & $50(2.9)$ & $14(8.0)$ & $40(70.2)$ & $<0.001$ & $<0.001$ \\
\hline${ }^{\star}$ Long-term mortality rate $(95 \% \mathrm{Cl})$ & $18.6(12.2-27.8)$ & $16.3(8.7-23.9)$ & $36.3(7.7-64.7)$ & 0.441 & $<0.001$ \\
\hline *Long-term follow-up MACCE & $51(3.0)$ & $11(6.7)$ & $1(5.6)$ & 0.020 & 0.429 \\
\hline
\end{tabular}

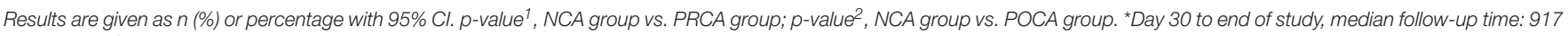

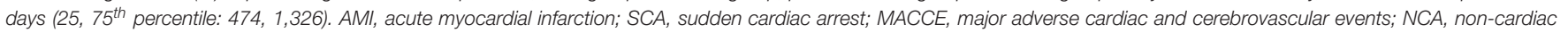
arrest; PRCA, pre- revascularization cardiac arrest; POCA, post-revascularization cardiac arrest.

the average stenosis percentage of culprit vessel in the PRCA group and POCA group was similar to that in the NCA group (all $p>0.05$ ).

The pre-PCI TIMI flow degree in culprit vessel in PRCA and POCA groups was not significantly different compared to that in the NCA group; however, a lower percentage of TIMI flow three restorations was observed in the PRCA group and POCA group compared to that in the NCA group (PRCA and POCA vs. NCA; $85.5 \%$ and $86.0 \%$ vs. $93.4 \%, p=0.001$ and $p=0.002$, respectively). We found a higher proportion of three-vessel disease in the POCA group compared to that in the NCA group ( $42.1 \%$ vs. $27.0 \%, p=0.012)$. However, we did not observe the significant intergroup difference in culprit vessel calcification, chronic total occlusion (CTO), and collateral circulation between patients without and with SCA regardless of type (all $p>0.05$ ).

In addition, post-PCI systolic and diastolic blood pressures were significant lower in patients with POCA and PRCA compared to those in patients with NCA (all $p<0.05$ ). Significant higher CTFC was observed in patients with SCA (PRCA and POCA) than in patients without SCA (40.0 and 45.0 vs. 38.0 frames, $p=0.037$ and $p=0.012$, respectively).

\section{0-Day and Long-Term Survival Rate}

Overall, $95.7 \%(1,871 / 1,956)$ of the patients were alive at the time of discharge. The in-hospital mortality rates of PRCA and POCA groups were higher than that of the NCA group (6.3 and $68.4 \%$ vs. $2.0 \%$; both $p<0.05$ ) (Table 3). Because a significant portion of patients in Asian countries opted to return home when the living chance was very low and their status at discharge were alive, we chose 30-day mortality to evaluate short-term survival. The median follow-up time from day 30 to end of the study in 30-day survivors was 917 days. Additionally, the 1-year follow-up rate and 3-year follow-up rate resulted to be 83.2 and $45.1 \%$, respectively.

As demonstrated in Table 3 and Figure 2, the 30-day survival was lower both in patients with PRCA and POCA when compared to patients with NCA $(8.0 \%$ and $70.2 \%$ vs. $2.9 \%$, both $p<0.001$ ). Among 30-day survivors, patients with POCA still showed worse survival prognosis during long-term follow-up than those without SCA occurrence $(p<0.001)$ (Table 3 and Figure 3). However, long-term cumulative mortality rate was not significantly different between NCA and PRCA groups among 30 -day survivors (18.6 vs. $16.3 \%, p=0.441$ ).

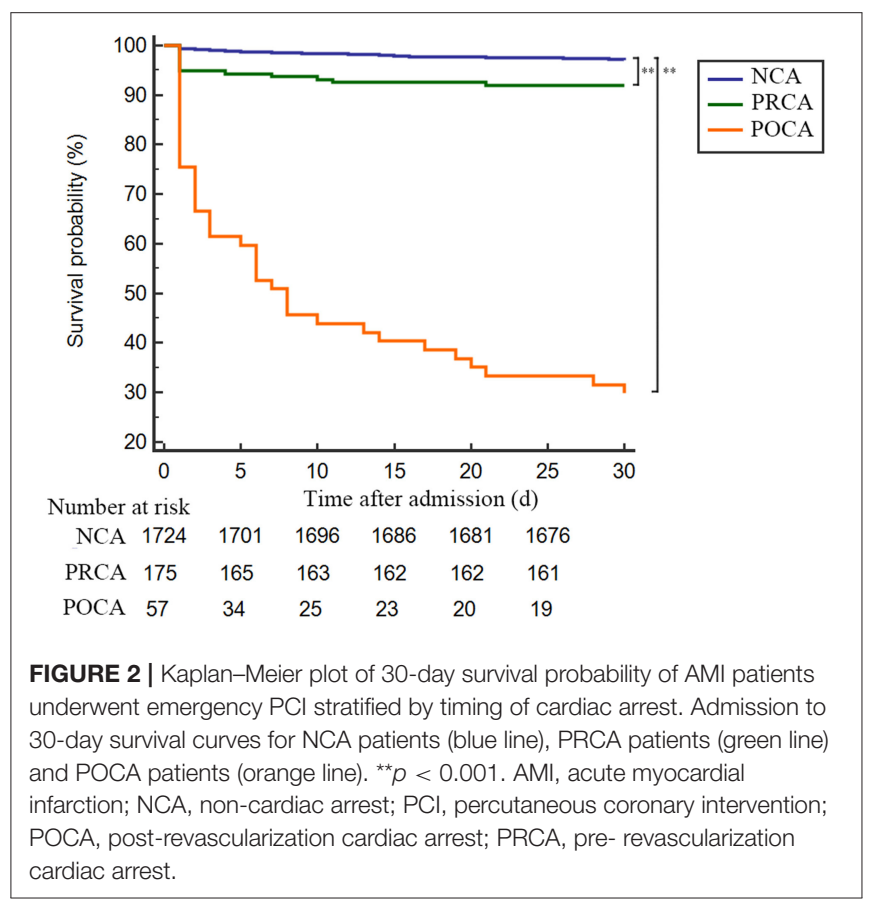

In the POCA group, we recorded shockable rhythm (VF/pVT) in 21 patients $(36.8 \%)$ and non-shockable rhythm (pulseless electrical activity/asystole) in the other 36 patients (63.2\%). Among POCA population, we found that non-shockable rhythm was associated with poor 30-day survival prognosis but similar survival prognosis in long-term follow-up, compared to shockable rhythm patients ( $p=0.032$ and $p=0.232$, respectively) (Figure 4).

\section{Independent Predictors for POCA}

In univariate Logistic binary regression analysis, age, Killip degree, diabetes, BNP, LVEF, Lactate, D-D dimer, creatinine, CK-MB, post-PCI SBP and DBP, atrial fibrillation, heart failure, culprit vessel of LM, and post-PCI CTFC were identified predictors for POCA occurrence. After adjustment for confounders, multivariate Logistic regression showed that Killip class 3/4 (OR 45.73, 95\%CI 12.03-173.78, $p<0.001$ ), high creatinine (OR 1.33, 95\%CI 1.09-1.64, $p=0.006)$, atrial fibrillation (OR 5.39, 95\%CI 1.45-20.04, $p=0.001$ ), 


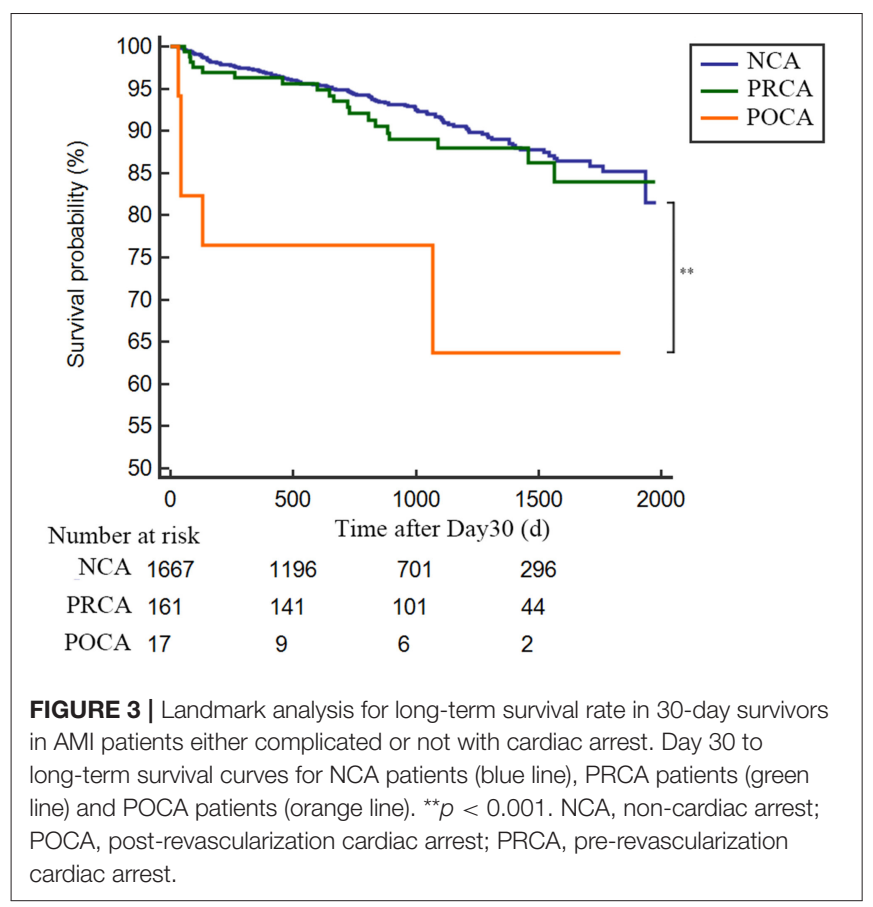

and higher maximum CK-MB (OR 1.30, 95\%CI 1.091.54, $p=0.002$ ) were independent risk factors for POCA (Table 4).

\section{Risk Factors for All-Cause Mortality During Long-Term Follow-Up}

Subsequently, we utilized univariate and multivariate COX regression analyses to assess predictors for long-term all-cause mortality. After adjustment for confounders, the following variables were identified as independent risk factors for longterm mortality (day 30 to end of study): POCA (HR 8.87, 95\%CI 2.26-34.72, $p=0.002$ ), older age (HR 1.04, 95\%CI 1.011.07, $p=0.003$ ), atrial fibrillation (HR 2.57, 95\%CI 1.13-5.81, $p=0.024$ ), heart failure (HR 2.78, 95\%CI 1.61-4.81, $p<0.001$ ), three-vessel coronary artery disease (HR 2.36, 95\%CI 1.36-4.09 $p=0.002$ ), and post-PCI CTFC (HR 0.98, 95\%CI 0.96-1.00 $p=0.025)$ (Table 5).

\section{DISCUSSION}

\section{Main Findings}

We investigated the incidence and prognostic influence of SCA (PRCA and POCA) in 1,956 consecutive patients with AMI who were admitted alive and underwent subsequently emergency PCI, and found that: (1) there were 175 patients (8.9\%) and 57 patients $(2.9 \%)$ experienced PRCA and POCA, respectively; (2) both PRCA and POCA were associated with higher 30-day mortality rate compared to the NCA group (8.0 and $70.2 \%$ vs. $2.9 \%$, both $p<0.001$ ); and (3) PRCA did not lead to poorer survival prognosis during long-term follow-up (median time of 917 days) in patients with AMI survived the first 30 days. In the contrast, POCA occurrence showed residual adverse influence on long-term survival prognosis in day 30 survivor population. (4) The independent predictors for POCA included Killip class 3/4, higher creatinine and maximum CK-MB, and atrial fibrillation. (5) Furthermore, multivariate analysis revealed that POCA was the strongest independent risk factor for mortality from day 30 to end of the study.

\section{Pre-Revascularization SCA Show Limited Adverse Impact on Long-Term Survival}

Pre-hospital SCA has been demonstrated to be associated with poor survival prognosis in some studies. In contrast to patients with AMI in the thrombolysis era who started revascularization therapy by intravenous thrombolytic therapy since hospitalization, most patients in the present PCI era got recovery of coronary artery blood perfusion after percutaneous transluminal coronary angioplasty or stent implantation in the catheter laboratory. Most previous classified the patients who experienced SCA before artery recanalization in catheter laboratory as in-hospital cardiac arrest (IHCA) group and patients with SCA before arrival at hospital as out of hospital cardiac arrest (OHCA), which might lead to data biases in survival analysis. Indeed, our study observed pre-hospital SCA in 150 patients with myocardial infarction (7.7\%) and 25 cases of SCA $(1.3 \%)$ in the catheter laboratory before coronary artery recanalization. The mechanisms of pre-hospital SCA and pre-revascularization SCA in the emergency catheter laboratory should be similar, and the clinical characteristics are comparable.

Numerous studies have reported the adverse impact of prehospital SCA on patients with AMI. One report demonstrated that only a quarter of the OHCA victims got a return of spontaneous circulation, and only $1 / 10$ th of them could survive to discharge (8). Garot et al. (9) studied 186 consecutive patients with AMI complicated with successfully resuscitated OHCA who were subsequently admitted in cardiac care unit. They found a survival rate of $55.4 \%$ at the timing of discharge. However, no death event was described during 6-month follow-up, which might be due to the limited population number. In a large population study, Karam et al. enrolled 13,253 patients with STEMI managed by emergency medical system and reported $29.8 \%$ discharge mortality in OHCA compared to $4.0 \%$ in patients without SCA (10). Their study not only enrolled patients admitted alive but also those who died before arrival at hospital to ensure the reliability of mortality analysis. The discharge mortality rates of patients complicated with or without prehospital SCA were higher than that reported in the present study, which could be explained by different population inclusions. However, the study did not further investigate the post-discharge survival prognosis among patients who were discharged alive, which limited the prognosis predicting value on long-term outcome. Another study found a significantly higher in-hospital mortality rate in patients with STEMI complicated with OHCA than patients without SCA (13.8 vs. 3.4\%), whereas the 1-year survival outcome in discharge survivors between the two groups was similar (11).

Sideris et al. (12) observed impaired admission survival (40.8\%) and favorable 5-year survival after discharge (92.2\%) 


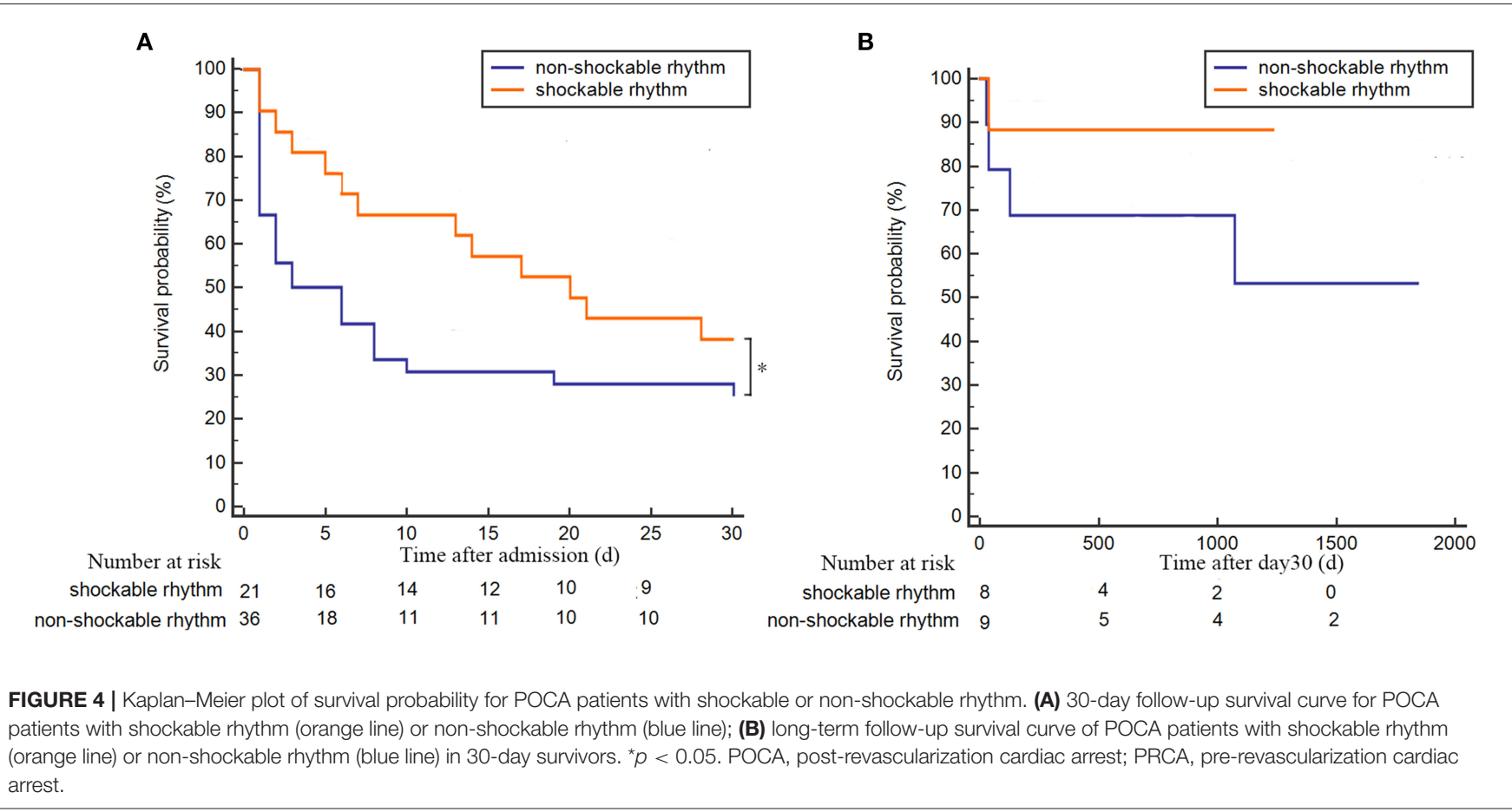

TABLE 4 | Independent predictors of POCA occurrence.

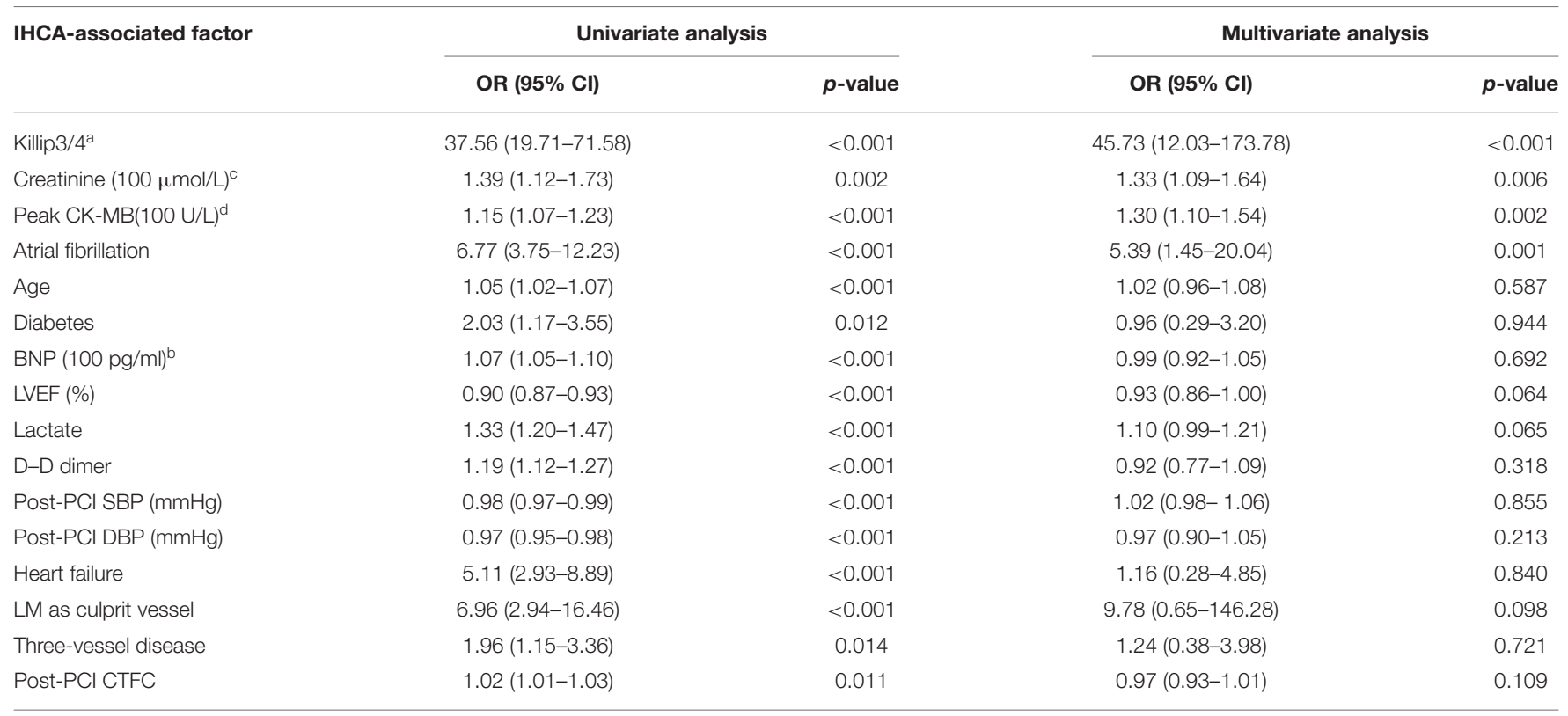

${ }^{a}$ Compared with Killip class 1/2; bor every $100 \mathrm{pg} / \mathrm{ml}$ increase in BNP; ' for every $100 \mu \mathrm{mol} / \mathrm{L}$ increase in blood creatinine; ${ }^{d}$ for every $100 \mathrm{U} / \mathrm{L}$ increase in maximum CK-MB. BNP, brain natriuretic peptide; CK-MB, MB isoenzyme of creatine kianse; CTFC, corrected TIMI frame count; IHCA, in-hospital cardiac arrest; LM, left main artery; LVEF, left ventricular ejection fraction; NCA, non-cardiac arrest; DBP, dilation blood pressure; SBP, systolic blood pressure; PCl, percutaneous coronary intervention; PRCA, pre- revascularization cardiac arrest; POCA, post-revascularization cardiac arrest.

among patients with pre-hospital SCA complicated with cardiogenic origin (ACS) (12). Similarly, Kvakkestad et al. (11) also reported a high 8-year survival (77.6\%) among patients with AMI with witnessed OHCA, who survived the first 30 days. Previous studies suggested that the 5-year survival rates after discharge in OHCA populations varied from 41 to $84 \%$ depending on different etiologies and inclusion criteria (13-15). However, the good long-term survival outcome of patients with PRCA of presumed cardiac origin, who survived the first 30 days, is convincing. 
TABLE 5 | Predictors of all-cause mortality in long-term mortality (day 30 to end of study).

\begin{tabular}{|c|c|c|c|c|}
\hline & \multicolumn{2}{|c|}{ Univariate analysis } & \multicolumn{2}{|c|}{ Multivariate analysis } \\
\hline & HR (95\% Cl) & $p$-value & HR (95\% Cl) & $p$-value \\
\hline POCA & $4.96(2.19-11.22)$ & $<0.001$ & $8.87(2.26-34.72)$ & 0.002 \\
\hline Age & 1.06 (1.05-1.07) & $<0.001$ & $1.04(1.01-1.07)$ & 0.003 \\
\hline Heart failure & 3.56 (2.75-4.62) & $<0.001$ & $2.78(1.61-4.81)$ & $<0.001$ \\
\hline Atrial fibrillation & $3.74(2.76-5.07)$ & $<0.001$ & $2.57(1.13-5.81)$ & 0.024 \\
\hline Three-vessel disease & $2.48(1.94-3.17)$ & $<0.001$ & $2.36(1.36-4.09)$ & 0.002 \\
\hline Post-PCI CTFC & $1.01(1-1.01)$ & 0.043 & $0.98(0.96-1.00)$ & 0.025 \\
\hline STEMI ${ }^{\mathrm{a}}$ & $1.43(1.11-1.85)$ & 0.006 & $1.55(0.79-2.29)$ & 0.203 \\
\hline Male gender & 0.69 (0.53-0.88) & 0.004 & $0.69(0.40-0.1 .18)$ & 0.173 \\
\hline Killip3/4b & $7.12(5.52-9.18)$ & $<0.001$ & $1.66(0.77-3.56)$ & 0.196 \\
\hline LVEF (\%) & 0.93 (0.92-0.95) & $<0.001$ & 0.98 (0.94-1.01) & 0.129 \\
\hline Post-PCI SBP (mmHg) & 0.99 (0.98-0.99) & $<0.001$ & 1.00 (0.99-1.01) & 0.994 \\
\hline Post-PCI DBP (mmHg) & 0.97 (0.96-0.98) & $<0.001$ & $0.98(0.96-1.01)$ & 0.124 \\
\hline $\operatorname{BNP}(100 \mathrm{pg} / \mathrm{ml})^{\mathrm{C}}$ & $1.05(1.04-1.07)$ & $<0.001$ & $0.98(0.95-1.01)$ & 0.124 \\
\hline Creatinine $(100 \mu \mathrm{mol} / \mathrm{L})^{\mathrm{d}}$ & $1.21(1.14-1.28)$ & $<0.001$ & 1.08 (0.79-1.48) & 0.637 \\
\hline D-D dimer (mg/L) & $1.11(1.08-1.15)$ & $<0.001$ & $1.02(0.94-1.10)$ & 0.678 \\
\hline Maximum CK-MB (100 U/L) ${ }^{e}$ & $1.07(1.03-1.10)$ & $<0.001$ & $1.03(0.97-1.10)$ & 0.337 \\
\hline Lactate(mmol/L) & 1.07 (1.05-1.09) & $<0.001$ & $1.02(0.97-1.78)$ & 0.393 \\
\hline IABP & 6.57 (4.74-9.10) & $<0.001$ & 1.52 (0.64-3.58) & 0.341 \\
\hline Vasoactive drug & $3.7(2.74-5.00)$ & $<0.001$ & $0.86(0.41-1.79)$ & 0.686 \\
\hline Ventilation & 6.41 (4.9-8.39) & $<0.001$ & $1.10(0.52-2.32)$ & 0.806 \\
\hline LM as culprit vessel & 5.35 (3.34-8.56) & $<0.001$ & $2.16(0.46-10.06)$ & 0.326 \\
\hline Stent implantation & 0.49 (0.36-0.66) & $<0.001$ & $0.72(0.21-2.43)$ & 0.595 \\
\hline Hypertension & $1.38(1.07-1.77)$ & 0.013 & $1.04(0.63-1.71)$ & 0.869 \\
\hline Diabetes & 1.65 (1.26-2.15) & $<0.001$ & $1.24(0.72-2.13)$ & 0.435 \\
\hline
\end{tabular}

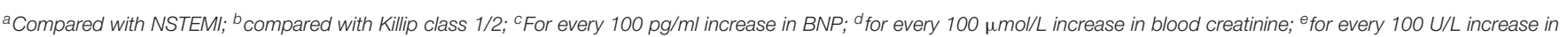

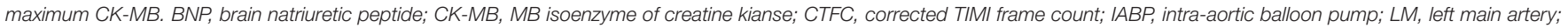

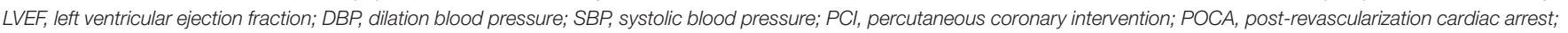
STEMI, ST-segment elevation myocardial infarction.

The main etiology underlying PRCA occurrence seems to be severe ventricular arrythmia. Demirel et al. (16) analyzed the 4,653 patients with STEMI and found that 326 patients $(7.0 \%)$ experienced pre-hospital cardiac arrest due to pVT or VF, which was similar with the rate of PRCA $(8.9 \%, 175 / 1,956)$ recorded in our study. In published reports, $\mathrm{VF} / \mathrm{pVT}$ contributed to nearly $80 \%$ of pre-hospital SCA among patients with AMI $(10,17)$.

The pathophysiology of VF/pVT during AMI is associated with a complex interaction of both environmental and genetic causes, including acute myocardial ischemia, ongoing ischemia, electrolyte disorder, and macro-reentry between ischemic and non-ischemic ventricular walls $(18,19)$. Although one would expect extensive ischemia regions and prolonged ischemia in AMI victims with witnessed SCA, recent evidence suggested that rhythmic vulnerability might partially account for some SCA cases, in which patients with AMI exhibit susceptibility to develop shockable arrhythmias soon after acute myocardial ischemia onset (10). Differed from patients with POCA, we did not find a significant difference in the PRCA group when compared to the NCA group upon proportion of three-vessel disease, stent implantation, and heart failure admission events.
We hypothesis that alterations on the resting membrane potential due to acute obstruction of coronary flow play a vital role in the onset of VF/pVT rhythm. And most cardiac functions of patients with AMI will be reserved once the restoration of coronary flow is achieved by immediate PCI therapy. This may partially explain the outstanding long-term survival outcome in patients with PRCA, who survived the first 30 days.

\section{Post-Revascularization SCA Show Adverse Prognostic Influence Beyond the First 30 Days}

In-hospital cardiac arrest was associated with high mortality at discharge, which varies from 47 to $85 \%$ depending on different criteria and inclusions (20-22). This contemporary study demonstrated a high 30 -day mortality of $70.2 \%$ in patients with AMI with POCA, and a high cumulative mortality of $36.3 \%$ from day 30 to end of the study (median follow-up time 917 days). Chen et al. (23) reported a 1-year survival rate of $60.2 \%$ in White race and $43.6 \%$ in Black race among IHCA survivors, which were comparable with our results based 
on Asian people (23). It has been reported that early IHCA, which contain a proportion of PRCA according to definition, were associated with relatively good survival when compared to delayed IHCA among STEMI population receiving primary PCI (20). The timing of SCA in the acute coronary syndrome population implies a significant determinant of clinical outcomes and underlying cause a difference in the etiologies. Differed from patients with OHCA, who often occur unexpectedly and most are of cardiac etiology, IHCA often deteriorate cardiac function previously and develop cardiogenic shock before terminal cardiac arrest (24).

Quite different from early SCA events, which are due to more easily reversible cause like shockable rhythm (pVT or VF), late SCA events often mean a multi-organ failure diseases and refractory shock. The POCA group appeared to be sicker even on admission than the PRCA group, with more than twice the lactate, higher BNP concentration, more proportion of patients with Killip class 3/4, more often IABP and ventilation use, and nearly 7 years older age on average. Additionally, coronary angiography demonstrated a low proportion of complete blood flow restoration, more frequent three-vessel disease, and more often LM or LAD ostial stenosis in patients with POCA than with NCA. Current research works focused on the antiarrhythmic effects of ischemic pre- and postconditioning. Andreas et al. found that preconditioning exerted antiarrhythmic properties during ischemia, whereas postconditioning exhibited antiarrhythmic effects after reperfusion, through downregulating ischemia-related miRNAs (25). Theofilos et al. observed weaker antiarrhythmic effects of postconditioning than preconditioning (26), indicating the antiarrhythmic properties of postconditioning remain to be further explored.

We found increased creatinine level is an independent risk factor for POCA, indicating a vital role of impaired renal function in the occurrence of fatal arrhythmia. Ventricular arrhythmia and sudden cardiac death risk are increased in patients with renal failure (27). Hyperkalemia, hypocalcemia, and hypomagnesemia have been demonstrated to be common complications of renal insufficiency. They show a cumulative effect on the atrioventricular and intraventricular conduction and facilitate ventricular fibrillation (28). And issues, such as serum phosphates and iron, parathyroid hormone level, renal function, hemoglobin and hematocrit, $\mathrm{pH}$, inflammatory markers, and standard 12-lead ECG, were also suggested to be monitored during treatment for electrolyte disorders (29). Our present study observed higher BNP levels in patients with PRCA and POCA. $\mathrm{BNP}$ has been proved to have protective effects against collagen formation and accumulation, and pathologic cardiac remodeling, which may via inhibition of rennin-angiotensin system, and systemic and renal sympathetic activity. BNP relatively increases heart rate and sinoatrial node activity in basal conditions (30). Moreover, BNP was demonstrated to increase cardiac conduction velocity, via activating multiple natriuretic peptide receptors, independent of cycle length (31). However, multivariate analysis showed higher BNP neither a risk factor for POCA occurrence nor predictor for adverse long-term survival outcome. GUIDEIT trial (32) and PRIMA II (33) failed to observe a favorable effect of BNP-guided treatment on all-cause mortality, heart failure readmissions, and median days alive outside of the hospital. However, some studies observed a slight favorable effect of BNPguided therapy among patients younger than 72 years of age $(34,35)$, suggesting the significance of monitoring BNP may differ between different populations.

\section{Independent Predictors Associated With Worse Survival Prognosis}

Unsurprisingly, older age and heart failure, which indicated weak body condition, were identified to be risk factors for long-term mortality. Despite similar degree of culprit vessel stenosis and pre-PCI TIMI flow grade, there was a lower rate of TIMI 3 flow achievement after intervention in the POCA group (86.0\%), when compared with NCA (93.4\%) group. The higher proportion of three-vessel coronary disease and high CTFC in patients with POCA also indicted difficulties in obtaining completed recovery of coronary reperfusion. Our results advocate the conclusion that early restoration of complete reperfusion (TIMI 3 flow) of the infarct-related artery in patients with AMI offers a mortality benefit $(36,37)$. We observed a relatively better 30 -day survival prognosis in POCA with shockable rhythm, compared to POCA with non-shockable rhythm, which was consist with the findings of previous reports $(22,38)$. Similarly, non-shockable rhythm was more frequently noted in initial arrhythmia of POCA (23). Unlike shockable rhythm which could be rapidly reversed by electric defibrillation, non-shockable rhythm is associated with multiorgan failure and unfavorable body condition. We demonstrated atrial fibrillation to be a strong independent predictor for longterm mortality in patients with SCA with AMI. In line with some studies, we found a significantly higher proportion of new-onset atrial fibrillation in patients with AMI complicated with SCA (5.1\% in PRCA and $19.3 \%$ in POCA, respectively), compared to patients without SCA (2.1\%) (39). In a systemic meta-analysis, new-onset atrial fibrillation was identified to be associated with poor survival prognosis in AMI population (40). Despite studies showed conflicting evidence in determining the influence of newonset atrial fibrillation on 30-day mortality, the adverse influence of both previous and new-onset atrial fibrillation after AMI on long-term survival prognosis was convincing (41).

\section{Limitations}

There are several limitations to be considered in our study. First, patients with AMI who died between symptom onset and arrival at the hospital were not included in the cohort study. Second, some out-of-hospital resuscitation-related variables were unavailable, including duration of total arrest time, cardiopulmonary resuscitation time, and initial arrhythmia at SCA. Third, we failed to collect data of Glasgow coma scale score to evaluate neurological outcomes. Additionally, troponin I and troponin T were not involved. Our department changed troponin assay kits during study period, and the early troponin assay kits only had a maximum of $50 \mu \mathrm{g} / \mathrm{L}$, resulting in a bias in statistical analysis. Fourth, we chose atrial fibrillation rhythm as ECG predictor for SCA. However, other outcome-related ECG issues, like interatrial block, deep terminal negativity of the $\mathrm{P}$ wave in V1, prolonged QT intervals, QRS 
duration, bundle branch block, ST segment depression, and premature ventricular contractions, were not considered for data missing (42).

\section{CONCLUSIONS}

Post-revascularization cardiac arrest was associated with a higher 30-day and long-term mortality rate in patients with AMI who underwent emergency PCI. By contrast, PRCA did not show a residual adverse effect on survival rate beyond day 30. Unfavorable prognostic factors for longterm survival included POCA, older age, atrial fibrillation, heart failure, three-vessel disease, and high CTFC. Our study indicated different survival outcomes of patients with SCA according to SCA timing, and strict medication guidance and more frequent clinical follow-up are suggested among POCA population.

\section{DATA AVAILABILITY STATEMENT}

The raw data supporting the conclusions of this article will be made available by the authors, without undue reservation.

\section{REFERENCES}

1. Spaulding CM, Joly LM, Rosenberg A, Monchi M, Weber SN, Dhainaut JF, et al. Immediate coronary angiography in survivors of out-of-hospital cardiac arrest. N Engl J Med. (1997) 336:1629-33. doi: 10.1056/NEJM199706053362302

2. Zeyons F, Jesel L, Morel O, Kremer H, Messas N, Hess S, et al. Out-of-hospital cardiac arrest survivors sent for emergency angiography: a clinical score for predicting acute myocardial infarction. Eur Heart J Acute Cardiovasc Care. (2017) 6:103-11. doi: 10.1177/2048872616683525

3. O'Gara PT, Kushner FG, Ascheim DD, Casey DE Jr., Chung MK, de Lemos JA, et al. 2013 ACCF/AHA guideline for the management of ST-elevation myocardial infarction: executive summary: a report of the American College of Cardiology Foundation/American Heart Association Task Force on Practice Guidelines. Circulation. (2013) 127:52955. doi: 10.1161/CIR.0b013e3182742c84

4. Peberdy MA, Callaway CW, Neumar RW, Geocadin RG, Zimmerman JL, Donnino M, et al. Part 9: post-cardiac arrest care: 2010 American Heart Association Guidelines for Cardiopulmonary Resuscitation and Emergency Cardiovascular Care. Circulation. (2010) 122:S768-86. doi: 10.1161/CIRCULATIONAHA.110.971002

5. Strote JA, Maynard C, Olsufka M, Nichol G, Copass MK, Cobb LA, et al. Comparison of role of early (less than six hours) to later (more than six hours) or no cardiac catheterization after resuscitation from out-of-hospital cardiac arrest. Am J Cardiol. (2012) 109:451-4. doi: 10.1016/j.amjcard.2011.09.036

6. Zanuttini D, Armellini I, Nucifora G, Carchietti E, Trillo G, Spedicato L, et al. Impact of emergency coronary angiography on in-hospital outcome of unconscious survivors after out-of-hospital cardiac arrest. Am J Cardiol. (2012) 110:1723-8. doi: 10.1016/j.amjcard.2012.08.006

7. Kim MJ, Ro YS, Shin SD, Song KJ, Ahn KO, Hong SO, et al. Association of emergent and elective percutaneous coronary intervention with neurological outcome and survival after out-of-hospital cardiac arrest in patients with and without a history of heart disease. Resuscitation. (2015) 97:115-21. doi: 10.1016/j.resuscitation.2015.08.019

8. Mozaffarian D, Benjamin EJ, Go AS, Arnett DK, Blaha MJ, Cushman $M$, et al. Heart disease and stroke statistics-2015 update: a report from the American Heart Association. Circulation. (2015) 131:e29-322. doi: $10.1161 /$ CIR. 0000000000000152

\section{ETHICS STATEMENT}

The studies involving human participants were reviewed and approved by Ethics Committee in clinical research of the First Affiliated Hospital of Wenzhou Medical University. The patients/participants provided their written informed consent to participate in this study.

\section{AUTHOR CONTRIBUTIONS}

All authors listed have made a substantial, direct and intellectual contribution to the work, and approved it for publication.

\section{FUNDING}

This study was supported by the National Natural Science Foundation of China (81600341), the Natural Science Foundation of Zhejiang Province (LQ15H020005), and Wenzhou Science Technology Bureau Foundation (Y20190616).

9. Garot P, Lefevre T, Eltchaninoff H, Morice MC, Tamion F, Abry $\mathrm{B}$, et al. Six-month outcome of emergency percutaneous coronary intervention in resuscitated patients after cardiac arrest complicating ST-elevation myocardial infarction. Circulation. (2007) 115:1354-62. doi: 10.1161/CIRCULATIONAHA.106.657619

10. Karam N, Bataille S, Marijon E, Tafflet M, Benamer H, Caussin $\mathrm{C}$, et al. Incidence, Mortality, and Outcome-Predictors of Sudden Cardiac Arrest Complicating Myocardial Infarction Prior to Hospital Admission. Circ Cardiovasc Interv. (2019) 12:e007081. doi: 10.1161/CIRCINTERVENTIONS.118.007081

11. Kvakkestad KM, Sandvik L, Andersen GO, Sunde K, Halvorsen S. Longterm survival in patients with acute myocardial infarction and out-of-hospital cardiac arrest: a prospective cohort study. Resuscitation. (2018) 122:41-7. doi: 10.1016/j.resuscitation.2017.11.047

12. Sideris G, Voicu S, Yannopoulos D, Dillinger J-G, Adjedj J, Deye N, et al. Favourable 5-year postdischarge survival of comatose patients resuscitated from out-of-hospital cardiac arrest, managed with immediate coronary angiogram on admission. Eur Heart J Acute Cardiovasc Care. (2014) 3:183-91. doi: $10.1177 / 2048872614523348$

13. Geri G, Dumas F, Bougouin W, Varenne O, Daviaud F, Pène F, et al. Immediate percutaneous coronary intervention is associated with improved short- and long-term survival after out-of-hospital cardiac arrest. Circ Cardiovasc Intervent. (2015) 8:e002303. doi: 10.1161/CIRCINTERVENTIONS.114.002303

14. Bergman R, Hiemstra B, Nieuwland W, Lipsic E, Absalom A, van der Naalt $\mathrm{J}$, et al. Long-term outcome of patients after out-of-hospital cardiac arrest in relation to treatment: a single-centre study. Eur Heart J Acute Cardiovasc Care. (2016) 5:328-38. doi: 10.1177/2048872615590144

15. Dumas F, White L, Stubbs BA, Cariou A, Rea TD. Long-term prognosis following resuscitation from out of hospital cardiac arrest: role of percutaneous coronary intervention and therapeutic hypothermia. J Am College Cardiol. (2012) 60:21-7. doi: 10.1016/j.jacc.2012.03.036

16. Demirel F, Rasoul S, Elvan A, Ottervanger JP, Dambrink JH, Gosselink AT, et al. Impact of out-of-hospital cardiac arrest due to ventricular fibrillation in patients with ST-elevation myocardial infarction admitted for primary percutaneous coronary intervention: impact of ventricular fibrillation in STEMI patients. Eur Heart J Acute Cardiovasc Care. (2015) 4:16-23. doi: $10.1177 / 2048872614547448$ 
17. Zeliaś A, Stepińska J, Andres J, Trabka-Zawicki A, Sadowski J, Zmudka K. Ten-year experience of an invasive cardiology centre with out-of-hospital cardiac arrest patients admitted for urgent coronary angiography. Kardiol Polska. (2014) 72:687-99. doi: 10.5603/KP.a2014.0088

18. Gheeraert PJ, Henriques JP, De Buyzere ML, Voet J, Calle P, Taeymans Y, et al. Out-of-hospital ventricular fibrillation in patients with acute myocardial infarction: coronary angiographic determinants. J Am College Cardiol. (2000) 35:144-50. doi: 10.1016/S0735-1097(99)00490-8

19. Tang L, Deng C, Long M, Tang A, Wu S, Dong Y, et al. Thrombin receptor and ventricular arrhythmias after acute myocardial infarction. Mol Med. (2008) 14:131-40. doi: 10.2119/2007-00097.Tang

20. Vallabhajosyula S, Vallabhajosyula S, Bell MR, Prasad A, Singh M, White RD, et al. Early vs. delayed in-hospital cardiac arrest complicating ST-elevation myocardial infarction receiving primary percutaneous coronary intervention. Resuscitation. (2019) 148:242-50. doi: 10.1016/j.resuscitation.2019.11.007

21. Kolte D, Khera S, Aronow WS, Palaniswamy C, Mujib M, Ahn C, et al. Regional variation in the incidence and outcomes of in-hospital cardiac arrest in the United States. Circulation. (2015) 131:1415-25. doi: 10.1161/CIRCULATIONAHA.114.014542

22. Girotra S, Nallamothu BK, Spertus JA, Li Y, Krumholz HM, Chan PS, et al. Trends in survival after in-hospital cardiac arrest. N Engl J Med. (2012) 367:1912-20. doi: 10.1056/NEJMoa1109148

23. Chen LM, Nallamothu BK, Spertus JA, Tang Y, Chan PS. Racial differences in long-term outcomes among older survivors of in-hospital cardiac arrest. Circulation. (2018) 138:1643-50. doi: 10.1161/CIRCULATIONAHA.117.033211

24. Morrison LJ, Neumar RW, Zimmerman JL, Link MS, Newby LK, McMullan PW, et al., et al. Strategies for improving survival after in-hospital cardiac arrest in the United States: 2013 consensus recommendations: a consensus statement from the American Heart Association. Circulation. (2013) 127:1538-63. doi: 10.1161/CIR.0b013e31828b2770

25. Spannbauer A, Traxler D, Lukovic D, Zlabinger K, Winkler J, Gugerell A, et al. Effect of ischemic preconditioning and postconditioning on exosome-rich fraction microRNA levels, in relation with electrophysiological parameters and ventricular arrhythmia in experimental closed-chest reperfused myocardial infarction. Int J Mol Sci. (2019) 20:2140. doi: 10.3390/ijms20092140

26. Kolettis TM, Vilaeti AD, Tsalikakis DG, Zoga A, Valenti M, Tzallas AT, et al. Effects of pre- and postconditioning on arrhythmogenesis in the in vivo rat model. J Cardiovasc Pharmacol Ther. (2013) 18:376-85. doi: 10.1177/1074248413482183

27. Al-Khatib SM, Stevenson WG, Ackerman MJ, Bryant WJ, Callans DJ, Curtis $\mathrm{AB}$, et al. $2017 \mathrm{AHA} / \mathrm{ACC} / \mathrm{HRS}$ guideline for management of patients with ventricular arrhythmias and the prevention of sudden cardiac death: a report of the American College of Cardiology/American Heart Association Task Force on Clinical Practice Guidelines and the Heart Rhythm Society. J Am Coll Cardiol. (2018) 72:e91-220. doi: 10.1016/j.jacc.2017.10.054

28. Bonato FOB, Canziani MEF. Ventricular arrhythmia in chronic kidney disease patients. J Bras Nefrol. (2017) 39:186-95. doi: 10.5935/0101-2800.20170033

29. Mozos I. Laboratory markers of ventricular arrhythmia risk in renal failure. Biomed Res Int. (2014) 2014:509204. doi: 10.1155/2014/509204

30. Caprnda M, Zulli A, Shiwani HA, Kubatka P, Filipova S, Valentova $\mathrm{V}$, et al. The therapeutic effect of B-type natriuretic peptides in acute decompensated heart failure. Clin Exp Pharmacol Physiol. (2020) 47:1120-33. doi: 10.1111/1440-1681.13290

31. Azer J, Hua R, Krishnaswamy PS, Rose RA. Effects of natriuretic peptides on electrical conduction in the sinoatrial node and atrial myocardium of the heart. J Physiol. (2014) 592:1025-45. doi: 10.1113/jphysiol.2013.265405

32. Felker GM, Anstrom KJ, Adams KF, Ezekowitz JA, Fiuzat M, Houston-Miller $\mathrm{N}$, et al. Effect of natriuretic peptide-guided therapy on hospitalization or cardiovascular mortality in high-risk patients with heart failure and reduced ejection fraction: a randomized clinical trial. JAMA. (2017) 318:713-20. doi: $10.1001 /$ jama.2017.10565
33. Stienen S, Salah K, Moons AH, Bakx AL, van Pol P, Kortz RAM, et al. NT-proBNP (N-Terminal pro-B-Type Natriureticcx Peptide)-guided therapy in acute decompensated heart failure: PRIMA II randomized controlled trial (Can NT-ProBNP-Guided therapy during hospital admission for acute decompensated heart failure reduce mortality and readmissions?). Circulation. (2018) 137:1671-83. doi: 10.1161/CIRCULATIONAHA.117.029882

34. Khan MS, Siddiqi TJ, Usman MS, Sreenivasan J, Fugar S, Riaz H, et al. Does natriuretic peptide monitoring improve outcomes in heart failure patients? A systematic review and meta-analysis. Int J Cardiol. (2018) 263:80-7. doi: 10.1016/j.ijcard.2018.04.049

35. Pufulete M, Maishman R, Dabner L, Mohiuddin S, Hollingworth W, Rogers $\mathrm{CA}$, et al. Effectiveness and cost-effectiveness of serum B-type natriuretic peptide testing and monitoring in patients with heart failure in primary and secondary care: an evidence synthesis, cohort study and cost-effectiveness model. Health Technol Assess. (2017) 21:1-150. doi: 10.3310/hta21400

36. Kim DW, Her SH, Park MW, Cho JS, Kim TS, Kang H, et al. Impact of postprocedural TIMI flow on long-term clinical outcomes in patients with acute myocardial infarction. Int Heart J. (2017) 58:674-85. doi: 10.1536/ihj.16-448

37. Vogt A, von Essen R, Tebbe U, Feuerer W, Appel KF, Neuhaus KL. Impact of early perfusion status of the infarct-related artery on short-term mortality after thrombolysis for acute myocardial infarction: retrospective analysis of four German multicenter studies. J Am Coll Cardiol. (1993) 21:1391-5. doi: 10.1016/0735-1097(93)90314-Q

38. Ohlsson MA, Kennedy LM, Juhlin T, Melander O. Evaluation of prearrest morbidity score and prognosis after resuscitation score and other clinical variables associated with in-hospital cardiac arrest in southern Sweden. Resuscitation. (2014) 85:1370-4. doi: 10.1016/j.resuscitation.2014. 07.009

39. Lee KH, Jeong MH, YoungkeunAhn, Kim SS, Rhew SH, Jeong YW, et al. One-year clinical impact of cardiac arrest in patients with first onset acute ST-segment elevation myocardial infarction. Int J Cardiol. (2014) 175:147-53. doi: 10.1016/j.ijcard.2014.05.002

40. Ren Y, Zeng RX, Li JJ, Guo LH, He DY, Li Y, et al. Relation of C-reactive protein and new-onset atrial fibrillation in patients with acute myocardial infarction: a systematic review and meta-analysis. Int J Cardiol. (2015) 190:268-70. doi: 10.1016/j.ijcard.2015.04.152

41. Gorenek B, Kudaiberdieva G. Atrial fibrillation in acute STelevation myocardial infarction: clinical and prognostic features. Curr Cardiol Rev. (2012) 8:281-9. doi: 10.2174/1573403128037 60857

42. Mozos I, Caraba A. Electrocardiographic predictors of cardiovascular mortality. Dis Markers. (2015) 2015:727401. doi: 10.1155/2015/ 727401

Conflict of Interest: The authors declare that the research was conducted in the absence of any commercial or financial relationships that could be construed as a potential conflict of interest.

Publisher's Note: All claims expressed in this article are solely those of the authors and do not necessarily represent those of their affiliated organizations, or those of the publisher, the editors and the reviewers. Any product that may be evaluated in this article, or claim that may be made by its manufacturer, is not guaranteed or endorsed by the publisher.

Copyright (c) 2021 Zhou, Lin, Xiang, Chen, Cai, Zhu, Zhou, Huang and Shan. This is an open-access article distributed under the terms of the Creative Commons Attribution License (CC BY). The use, distribution or reproduction in other forums is permitted, provided the original author(s) and the copyright owner(s) are credited and that the original publication in this journal is cited, in accordance with accepted academic practice. No use, distribution or reproduction is permitted which does not comply with these terms. 